\title{
Intercultural Institutional Competence Proposed Standards Evaluation Framework
}

\author{
Article by Marcos C. Ferreira \\ Ph.D, Education, Texila American University, Canada \\ E-mail:marcos@gmx.ca
}

\begin{abstract}
Educational institutional intercultural competence can only be fully achieved once accreditation bodies commit and embrace a systematic, coherent and explicit standardized framework and process of criteria, dispositions, institutional culture, attributes and policies that are aimed at fostering a real intercultural landscape that is beyond the rhetorical jargon often articulated in institutional mission and vision around the globe. Fostering the development of intercultural skills remains at the forefront of promoting understanding, respect and more equitable communities around the globe.

A clear set of institutional intercultural competence will further buttress accreditation processes and provide institutions with the opportunity to engage on a self-reflective process and to implement tangible and verifiable evidence that once analyzed and verified will validate best practices and the effectiveness of approaches. Hence, this study establishes why institutional intercultural competence is an important element in promoting the development of schools that are interculturally competent and explores the current limitations of international standards.

Moreover, this study reviews the three major accreditation bodies' (AdvancED, International Baccalaureate and Cambridge) standards of school accreditation and points that currently none have standards that directly endorses the principles of interculturalism based on the universal values of fairness that ought to be reflected and articulated in school's policies; respect which must be evident in the institution's commitment to promote a climate of acceptance and understanding; and fairness by establishing an institutional culture of inclusion and equality. Finally, this study presents a comprehensive set of institutional insterculturalism standards and criteria that serves a practical and tangible evaluative tool.
\end{abstract}

Keywords: Accreditation, Intercultural; Competence; 21st-century; International Baccalaureate; Equality.

\section{Introduction}

This study identifies an important lack of standards and, therefore, detrimental deficiency on the accreditation process of international K-12 educational institutions by three main accrediting bodies AdvancEd, Cambridge, the International Baccalaureate. Furthermore, it calls for the review of accreditation processes and, finally, it proposes an evaluative framework of school accreditation that clearly addresses and sets a clear evaluative framework for institutional intercultural competence.

While many institutions of higher education have policies on interculturalism, the same remains to be seen in K-12 schools - many of which are independent and privately owned schools currently authorized or accredited by the three major abovementioned accrediting bodies which themselves have limited scope in promoting accountability. Therefore, while the proposed framework serves as an additional tool for institutional self-study and reflection, its scope remains limited as it may not be translated into practical and tangible actions at the institutional level. Finally, interculturalism is a complex, layered and multifaceted, concept seen a global and cultural asset and welcomed by many, but it may be also considered a threat by some.

The human experience is characterized by a rich diversity of cultures, ethnicities, languages, races, and religions throughout our planet. We speak about 6909 languages (Anderson, 2017); and we embrace thousands of religious denominations divided amongst an important number of ethnic groups. One may 
DOI: $10.21522 /$ TIJAR.2014.04.02.Art014

ISSN: $2520-3088$

argue that the richness in diversity of the human experience is our greatest asset. However, as history has shown many times over, it can also serve as our greatest divider with catastrophic consequences when those differences are used to instill fear, prejudice and hate.

Regrettably, it is unlikely that we will ever be able to completely erase fear, prejudice and hate. However, as educators, we ought to do and deploy every tool we can to curb, diminish and eliminate fear of the "other" and to promote intercultural competence in our educational institutions. By promoting diversity, fairness and respect for all, we are systematically and institutionally contributing towards the betterment of our community and, undeniably, of humankind.

By the time young adult enter higher education, their perceptions and views of the "other" are often well-established and galvanized by their experience and exposure during their early years. Hence, the earlier we can foster intercultural competence, the greater impact we will have in promoting individuals' ability to behave and promote equality, fairness and respect. Therefore, this paper aims at providing a brief overview on the relevance of intercultural competence; the absence of standards for intercultural institutional competence in accreditation processes; and it proposes it presents a new rubric-framework for institutional intercultural competence.

Is institutional intercultural competence important?

On September 9, 2002, Israeli Prime Minister, Benjamin Netanyahu was scheduled to deliver a speech at Concordia University in Montreal, Quebec, Canada. The events that unfolded included riots, a swat squad intervention, tear gas, students and dignitaries stranded inside Concordia's F. Hall Building and a school community traumatized and divided. The event left Concordia's leadership, an institution characterized by diversity and tolerance, in utter shock and the community galvanized into two very diametrically opposed sides. The is following is Thomas Hecht who is a Holocaut offer a vivid account of the day:

"This was anti-Semitism. I was the object of their hatred ... which expressed itself with placards; with a kind of venom which I have not seen on the streets of a city since the horrible days of occupied, Nazioccupied Europe. What happened on the 9th of September was really a dark day for Concordia. And I think that the university will have to suffer the consequences of this. It will not come, the change will not come from one day to the other. The perception of Concordia will not be that of an institution where freedom of speech can be freely expressed. Because the way these thugs behaved was not any better than the people who were condemned for such behaviour in 1939 in Europe." (Canadian Broadcast Standards Council National Conventional Television Panel, 2004).

Every school, college or university community is unique and a reflection of its own cultural, social, and more often than what we would like to admit, the political landscape and it is naïve to think otherwise. Could the events that took place at Concordia on September 9, 2002 been prevented? Could the university leadership been more sensitive towards the large number of Palestian students on campus? Possibly. Nevertheless, it seems that any conjecture about how the situation could have handled past the event bears no impact on the past.

However one may feel about what became known nationally as the "Concordia University Netanyahu riot", Concordia's institutional experience reveals an important gap between what institutions aspire to be in terms of diversity, intercultural understanding and respect and the reality of the group dynamics, personal and social interests and the student population's diversity and institutional culture. Unless educational organizations also commit to support intercultural competence at the institutional level and translate that commitment into well-articulated policies, practices, learning opportunities and personal social development of every staff and student, intercultural competence cannot be truly achieved.

The need for developing intercultural competence have been highlighted as central to address and prevent social problematic issues such as racism, discrimination and hate speech and as an important tool to promote understanding. Huber (2012) recognizes the importance of education's role in fostering intercultural positive attributes, he argues: "Intercultural competence is a central precondition for every individual and since it is not automatically acquired, it needs to be developed, learned and maintained throughout life."

Review of accreditation process and limitations of current international accreditation standards. International accreditation bodies such as the AdvancED, Cambridge and the International Baccalaureate offer a framework and curriculum for international education, however, it should be noted that none of the 
organizations consider intercultural competence both at the organization and cohort levels as criteria for accreditation purposes. The review of literature revealed that many of the learning approaches suggested by the three organizations would indeed promote intercultural awareness. Nevertheless, they fall short of making organizational intercultural competence a standard or criteria for international accreditation. The table below offers a general overview of the current five accreditation standards used by AdvancED, Cambridge and the International Baccalaureate and the number of institutions authorized by each organization:

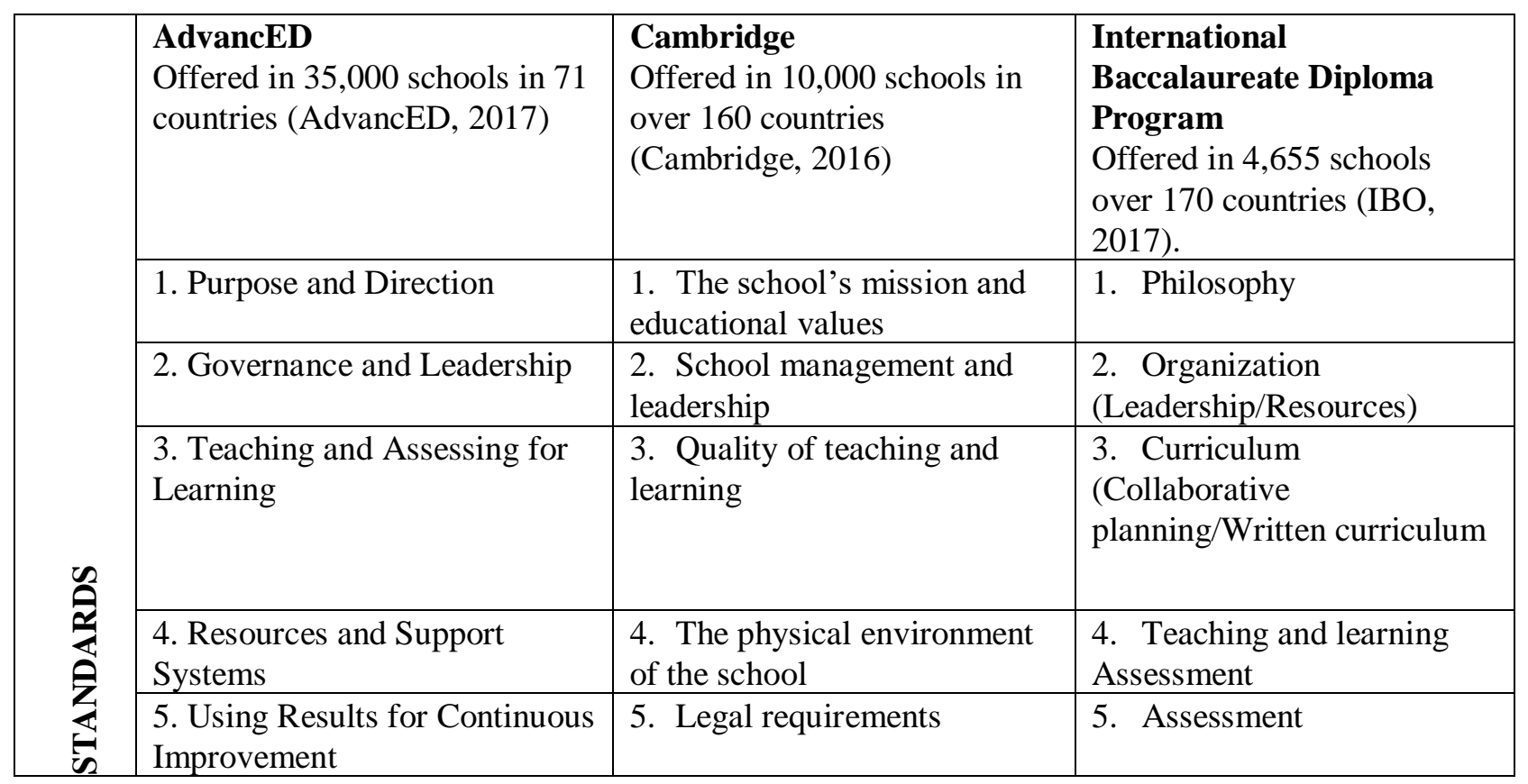

\section{Framing institutional intercultural competence}

\section{Policies that support intercultural competence - fairness}

In order to support intercultural competency, educational institution ought to develop and articulate comprehensive policies that are inductive of promoting equal treatment and intercultural awareness in very practical terms. For instance, Bennet (cited in Safie 2014) suggests that cultural competency entails cognitive, affective and behaviours applied to different contexts.

\section{Environment that promotes intercultural competence - respect}

United Nations Education and Scientific Cultural Organization (UNESCO) have been at the forefront of establishing international conventions and recommendations that puts intercultural competence at the forefront. For instance, as early as 1974, UNESCO established a pointed recommendation: "Education for International Understanding, Cooperation and Peace and Education relating to Human Rights and Fundamental Freedoms" which calls for the "need for understanding and respect for all peoples, their cultures, civilizations, values and ways of life." (UNESdCO, 2009). This can be best achieved in an environment and institutional atmosphere where trust and respect are achieved through dialogue, mutual understanding and the equal treatment of all.

\section{Educational programme that fosters intercultural competence - inclusive}

The, hallmark of intercultural education is diversity and, arguably, any institution aiming at adopting and embracing diversity ought to be inclusive and to take the necessary steps both in terms of resources and policies that promotes diversity beyond the veneer of bolstering its number of international students. An optimum inclusive academic community implies that its cohort regardless of background have an overall equal academic and social experience that takes into consideration individual and community identities (Council of Europe 2007). Additionally, its faculty and administration should be composed of 
DOI: $10.21522 / \mathrm{TIJAR} .2014 .04 .02 . A r t 014$

ISSN: $2520-3088$

professional from diverse backgrounds and be equipped with the intercultural attributes that the institution wishes to impart.

\section{The case for intercultural competence accreditation standards}

The role of intercultural awareness has been recognized as an important personal attribute and in promoting positive climate. Additionally, there is a wide range of assessment tools to evaluate intercultural competence, for instance, the Intercultural Communication Institute (2017) offers an important repository of resources and assessment tools that can be effectively deployed by organizations and school communities to foster intercultural awareness amongst its cohort, faculty and professional members. However, the literature review unearthed scant evidence that systematic resources and frameworks of intercultural competence that addresses educational institutions, leading to the question: How can school leadership evaluate its effectiveness in promoting intercultural effectiveness? Ironically, it is practically impossible to visit educational institutions that do not call for intercultural awareness or global citizenship and whilst the mantra is often repeated, there is little evidence of any measuring tools which allow for an objective and pragmatic evaluation and validation of existing policies, approaches and activities that foster intercultural competence.

Therefore, this study proposes that various international accreditation agencies, such as aforementioned, enshrine intercultural competence as a core standard leading to accreditation. The rubric/framework here proposed ought to provide international school communities around the globe the opportunity to engage in a self-assessment process that ought to be a collaborative exercise which brings together all communities aiming at promoting organizational intercultural accountability. 


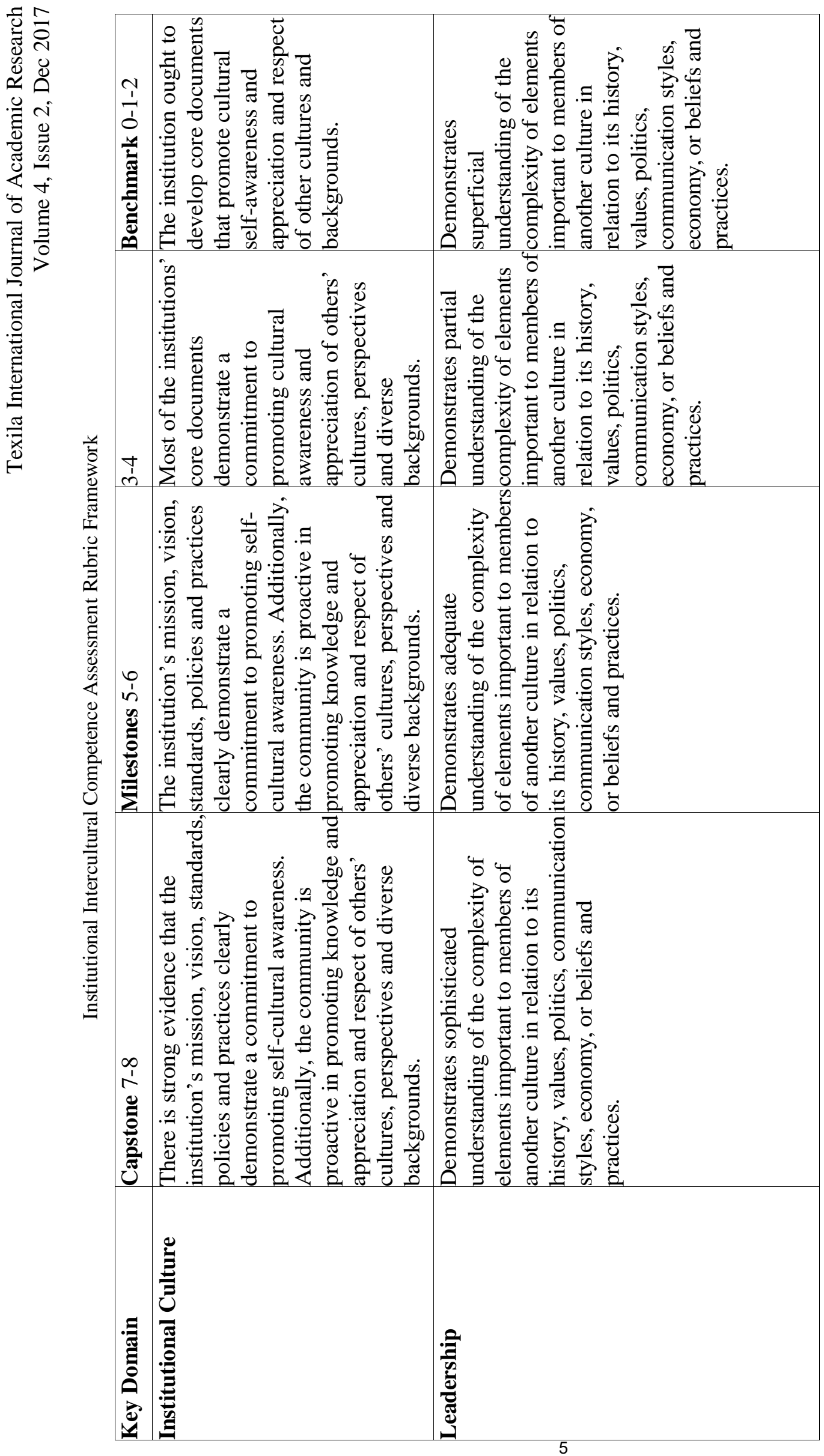




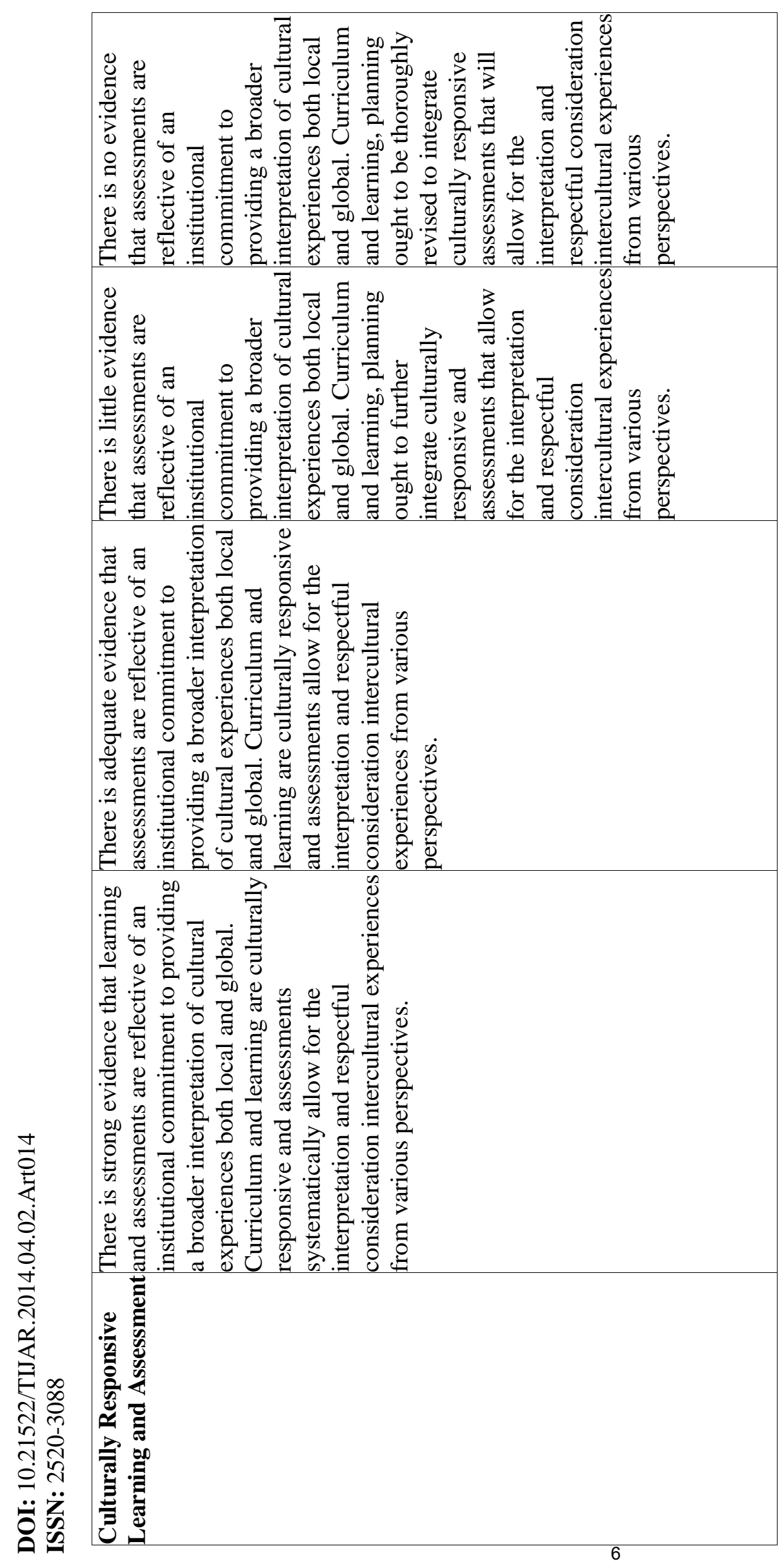




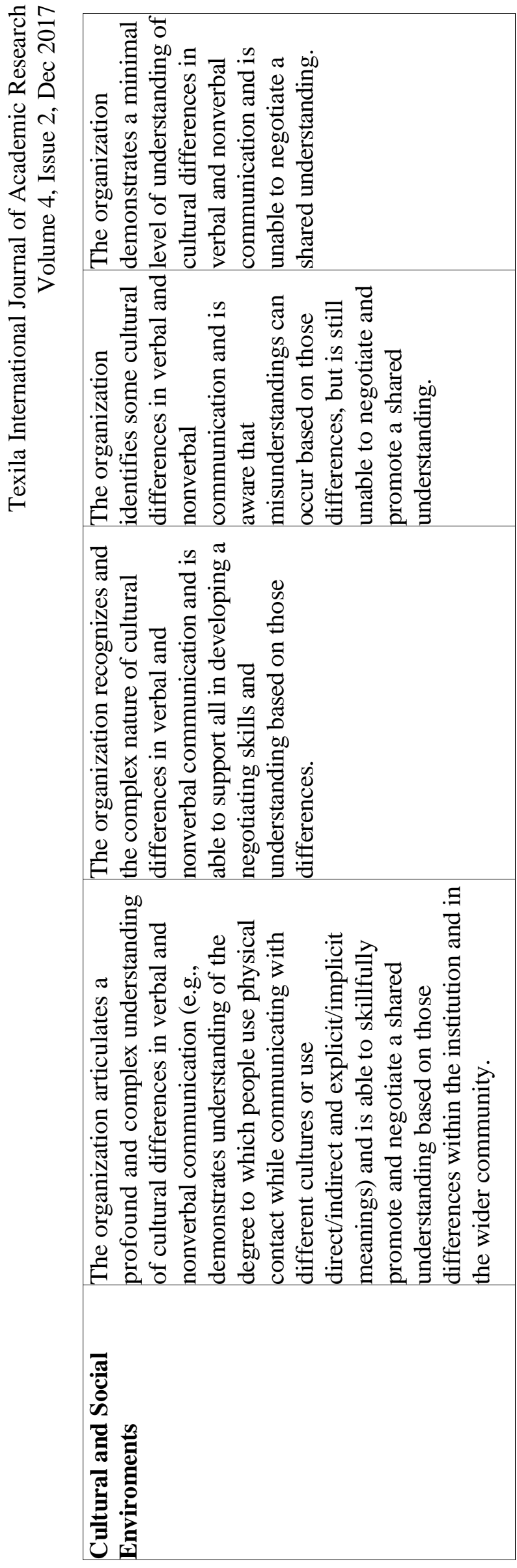




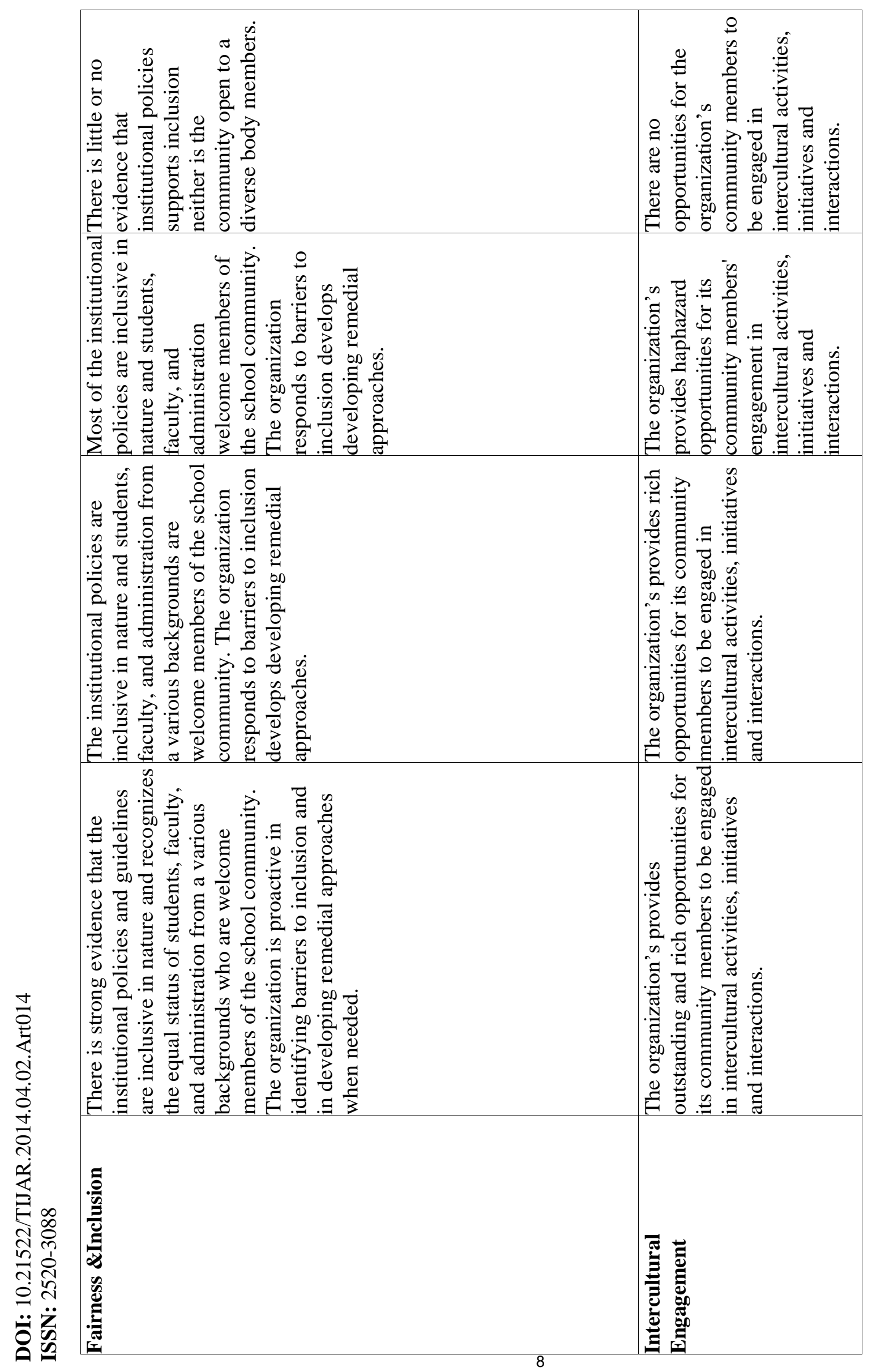




\section{Appllication and limitations}

While the proposed rubric/framework for intercultural competence assessment may serve as a selfevaluative tool or as a standard for international accreditation, by its own nature it is limited in scope since international accreditation organizations have no reinforcement or legal power and and while many organizations such as UNESCO and the Council of Europe have traditionally emphasized the importance of interculturalism and the importance and urgency of promoting intercultural competence, they are limited in legal and political scope - issues that are beyond the scope of this study, nevertheless, important to be acknowledged.

Nevertheless, it is important that accreditation agencies articulate clear expectations and evaluative criteria for the promotion of intercultural competence as a pre-condition for school's international authorization. In that endeavor, the implementation of the rubric/framework here included aims at providing a practical self-assessment/measuring tool which will enable both the accreditation agency and the school community to assess its policies, organizational culture, teaching and learning, approaches and attitudes in a continuum of effectiveness.

Furthermore, whilst many institutions have effectively implemented intercultural policies, important obstacles remain related to the nature of interculturalismin itself. Deardorff (2010) posits that many postsecondary institutions aim at internationalization to foster intercultural competence. However, she notes, "Yet few universities address the development of interculturally competent students as an anticipated outcome of internationalization in which the concept of "intercultural competence" is specifically defined" Deardoff's survey of international scholars on the nature of intercultural competence revealed a variety of opinions and definitions and she posits this attests to the complex and multilayered nature intercultural competence.

\section{Conclusion}

There is an underlying assumption that the more diverse a school population is, the more likely the community and its members are to emulating the attributes associated with intercultural competence. However, as the University of Concordia 2009's events illustrates, that, is an unnecessarily risky assumption with serious organizational and societal implications.

As noted at the outset of this study, the promotion of intercultural competence ought to be at the forefront of fostering fairness, respect and equality. In the age of globalization, we ought to promote the cultural skills our students and faculty need to be truly functional in whatever capacity they decide best fits their aspirations to contribute to their communities both locally and globally. In doing so, we will promote individuals who are able to assert positively and constructively with their own identities while able to engage with the "other" with equality, fairness and respect.

Finally, it is a well-accept reality that schools and teachers have a great impact on the development and students' outlook in life. As educators, we are privileged and have a unique opportunity to embrace and impart intercultural competence and every school community and every classroom teacher have a moral and social obligation to do so.

\section{References}

[1].AdvancED. (2011). AdvancED Standards For Quality Schools. Retrieved 12 March 2017 from http://www.advanc-ed.org/sites/default/files/documents/SchoolStndsNolevels.pdf.

[2].AdvancED. (2017). We are AdvancED. Retrieved 10 March 2017 from http://www.advanc-ed.org/about-us.

[3].Anderson, S.R. (2017). How many languages are there in the world? Retrieved 20 March 2017 from http://www.linguisticsociety.org/content/how-many-languages-are-there-world.

[4].Association of American Colleges and Universities. (2017). Intercultural Knowledge and Competence Value Rubric. Retrieved 12 March 2017 from

http://www.crlt.umich.edu/sites/default/files/resource_files/InterculturalKnowledgeVALUErubric.pdf.

[5].Cambridge. (2016). Becoming a Cambridge International School - A guide to the registration process. Retrieved

11 March 2017 fromhttp://www.cie.org.uk/images/163193-becoming-a-cambridge-international-school.pdf.

[6].Cambridge. (2016). Who We Are. Retrieved 11 March 2017 from http://www.cie.org.uk/about-us/who-we-are/. 
DOI: $10.21522 /$ TIJAR.2014.04.02.Art014

ISSN: $2520-3088$

[7].Canadian Broadcast Corporation. (2002). Montreal Protesters Force Cancellation of Netanyahu Speech. Retrieved 12 March 2017 from http://www.cbc.ca/news/canada/montreal-protesters-force-cancellation-ofnetanyahu-speech-1.312529.

[8].Canadian Broadcast Standards Council National Conventional Television Panel. (2004). Confrontation at Concordia (documentary).Transcript (Appendix A to CIII-TV (Global Television) re Confrontation at Concordia (CBSC Decision 02/03-1340, -1368, -1514 and -1530, April 26, 2004)). Retrieved 15 March 2017 from http://www.cbsc.ca/english/decisions/2004/040511appendixA.pdf.

[9].Community Tool Box. (2017). Section 7. Building Culturally Competent Organizations - University of Kansas. Retrieved 17 March 2017 from http://ctb.ku.edu/en/table-of-contents/culture/cultural-competence/culturallycompetent-organizations/main.

[10]. Deardorff , D. K. (2010). Identification and Assessment of Intercultural Competence as a Student Outcome of Internationalization.Journal of Studies in International Education. Retrieved 15 March 2017 from http://www.tru.ca/_shared/assets/Identification-and-Assessment-Intercultural-Competence29342.pdf, 234.

[11]. European Commission. (2012). Intercultural Competence Curriculum Framework. Retrieved 16 March 2017 from http://www.pictllp.eu/download/PICT_Curriculum_Framework.pdf.

[12]. Huber, J. (2012). Intercultural competence for all Preparation for living in a heterogeneous world.Retrieved 15 March 2017 fromhttp://www.coe.int/t/dg4/education/pestalozzi/Source/Documentation/Pestalozzi2_EN.pdf.

[13]. International Baccalaureate Organization. (2016). Guide to school authorization: Diploma Programme. Retrieved 12 March 2017 from http://www.ibo.org/globalassets/publications/become-an-ib-school/dp-guide-schoolauthorization-en.pdf.

[14]. Safie, O. (2014). Intercultural and Interdisciplinary Exploration Assessment Overview.Retrieved 22 March 2017 from http://pitweb.pitzer.edu/institutional-research/wp-content/uploads/sites/33/2015/07/IIE-Report-FinalVersion.pdf.

[15]. United Nations Education and Scientific Cultura Organization. (2009). Policy Guidelines of Inclusion in Education. Retrieved 20 March 2017 from http://unesdoc.unesco.org/images/0017/001778/177849e.pdf

[16]. University of Jyväskylä. (2017). What is an Interculturally Competent Person Like? Retrieved 18 March 2017 from https://moniviestin.jyu.fi/ohjelmat/hum/viesti/en/ics/54. 